\title{
Papers
}

\section{Individual income, income distribution, and self rated health in Japan: cross sectional analysis of nationally representative sample}

\author{
Kenji Shibuya, Hideki Hashimoto, Eiji Yano
}

\begin{abstract}
Objective To assess the effects on self rated health of individual income and income distribution in Japan.

Design Cross sectional analysis. Data collected on household income, self rated health, and other sociodemographic characteristics at the individual level from comprehensive survey of the living conditions of people on health and welfare in a nationally representative sample from each prefecture.

Setting Prefectures in Japan.

Participants 80899 people aged $>15$ years with full records in survey.

Main outcome measures Dichotomous variable for self rated health of each respondent (0 if excellent, very good or good; 1 if fair or poor).

Results Inequality in income at the prefecture level measured by the Gini coefficient was comparable with that in other industrialised countries. Unadjusted odds ratios show a 14\% increased risk (odds ratio 1.14, 95\% confidence interval 1.02 to 1.27 ) in reporting poor or fair health for individuals living in prefectures with higher inequality in income. After adjustment, individual income was more strongly associated with self rated health than income inequality. Additional inclusion of regional effects showed that median income at the prefecture level was inversely related to self rated health.

Conclusions Individual income, probably relative to the median prefecture income, has a stronger association with self rated health than income inequality at the prefecture level.
\end{abstract}

\section{Introduction}

A series of international comparative analyses has consistently shown that the health of a population, with indicators such as life expectancy, depends not just on the absolute size of the national income but on how that income is distributed. ${ }^{2}$ Recently, studies on income distribution and health have been extended to analysis within a nation. Results suggested that large inequalities in income within a society may be an important source of regional variations in health. ${ }^{3-6}$

Several possible mechanisms through which income and its distribution may affect health have been proposed. ${ }^{4-10}$ Some studies support the idea that income distribution within a region itself influences people's health, while others state that the absolute level of individual income is one of the determinants of individual health. ${ }^{5}$ Furthermore, there is a hypothesis that what affects health is individual income relative to average income in a region. ${ }^{10}$

As ecological studies are prone to aggregation and confounding bias, individual level studies have been carried out to assess the independent effects of income inequality after adjustment for an individual's income. ${ }^{8}{ }^{10}$ These studies have exclusively been carried out in the United States, and they have shown mixed results. ${ }^{911-16}$ It is still not clear whether the relation between income, income distribution, and health at the individual level is a universal phenomenon and whether it can be explained by the proposed mechanisms.

From the early 1960 s to the late 1980 s Japan achieved the narrowest income differentials in industrialised countries and the highest life expectancy in the world. Several authors have attributed such a rapid improvement in population health to the more egalitarian social system in Japan. ${ }^{17}$ However, inequality in income in Japan since the late 1980s has increased at a much faster pace than in other industrialised countries. $^{19}$

We examined the independent effects of income and its distribution on health during the period of widening income disparity in Japan. We hypothesised that any effects would become clear when the level of income inequality reached that observed in Western nations and that such effects would appear first on self rated health at the individual level and later on mortality at the population level. We examined the effects of individual income and its distribution on individuals' self rated health by using a nationally representative sample from the Japanese population.

\section{Methods}

Data source

We used data from the 1995 comprehensive survey of the living conditions of people on health and welfare (LCPHW) by the Ministry of Health and Welfare. ${ }^{20}$ This survey interviewed all household members within 5100 area units, randomly sampled from all prefec-

\author{
Department of \\ Hygiene and Public \\ Health, Teikyo \\ University School of \\ Medicine, Tokyo, \\ Japan \\ Kenji Shibuya \\ assistant professor \\ Hideki Hashimoto \\ assistant professor \\ Eiji Yano \\ professor and \\ chairman \\ Correspondence to: \\ H Hashimoto \\ hhashimo@med. \\ teikyo-u.ac.jp \\ BMJ 2002;324:1-5
}


Table 1 Descriptive statistics of economic variables in Japan

\begin{tabular}{lll} 
Economic variable & Mean (SD) & Median (range) \\
\hline Prefecture level ${ }^{*}$ & & \\
\hline Median prefecture income (million yen) & $3.02(0.52)$ & $3.13(1.80-4.04)$ \\
\hline Gini coefficient & $0.36(0.03)$ & $0.36(0.31-0.45)$ \\
\hline Individual level†: & & \\
\hline Sample household income, adjusted for household size (million yen) & $4.08(0.33)$ & $3.48(0.05-83.00)$ \\
\hline${ }^{*}$ Estimated from original data ( $\left.\mathrm{n}=103040\right)$. & & \\
†Based on sample used in analysis $(\mathrm{n}=80899)$. &
\end{tabular}

tures in Japan. Hyogo prefecture was excluded from the 1995 survey because it was severely affected by an earthquake at that time. This nationally representative interview survey contains household and individual information on demographics, health, illness profiles, and use of health services. After we excluded records with missing values on key variables (4747) and excluded those from people aged $\leqslant 15$ years (17 394), we obtained a total of 80899 individual observations for analysis.

\section{Measure of self rated health}

A recent review of various community studies showed that self rated status is strongly correlated with more objective measures of health, such as mortality, independent of medical, behavioural, and psychosocial risk factors. ${ }^{21}$ The 1995 survey elicited the respondent's perceived overall health status by asking, "What is your current health status: excellent, very good, good, fair, or poor?" We created a dichotomous variable for self rated health ( 0 if excellent, very good, or good; 1 if fair or poor), following the previous individual level studies in the United States..$^{11-13} 15$

\section{Independent variables}

We used age, sex, and marital status (never married, married, separated, divorced) as demographic covariates and determined whether the respondent had had a medical check up in the year before the survey. As Japan has a universal health insurance system, variables related to health insurance were not included in the analysis.

From the 1995 survey we obtained information on annual household income before tax, including benefits and transfer payment. To obtain individual level income we adjusted household income for household size with equivalence elasticity of 0.5 , as used in previous studies. ${ }^{22}$ We used the Gini coefficient as a measure of income distribution within a prefecture and divided the sample into quarters. Because of the skewed distribution of household income we used median prefecture income as a representative value of absolute income in the analysis.

\section{Statistical analysis}

The stratified design of the national survey requires special analysis for unequal sample probabilities and clustered observations and consequent underestimation of errors. ${ }^{24}$ For this reason, we used the statistical package SUDAAN (version 7.5.6, Research Triangle Institute, NC), which takes into account the design effects of the survey to estimate appropriate standard errors. ${ }^{25}$ We made further adjustment with the weights provided by the Ministry of Health and Welfare to correct for unequal probability selection and nonresponse bias.
We tested in a hierarchical way three types of logistic regression models to assess the relation among income, income distribution, and self rated health. Firstly, we carried out univariate analyses of all the explanatory variables on self rated health. Secondly, we used a simple regression to estimate the relation between two ecological variables (that is, income inequality and median income at the prefecture level) and self rated health (model 1). Thirdly, we adjusted individual income as well as other individual characteristics in addition to the ecological variables (model 2). Fourthly, we further adjusted for the possible effects specific for a region by including dummy variables for 12 geopolitical blocks in Japan, as unspecified characteristics of regions may confound the relation between income inequality and health (model 3). ${ }^{11}{ }^{26}$ Each regional block comprises three to six prefectures, except Hokkaido. Finally, we reanalysed the data stratified by age ( $\leqslant 65$ and $>65$ years), sex, and income to test whether the effects of income inequality vary across the stratum. ${ }^{13}$

Table 2 Sample characteristics (unweighted) of people in Japan

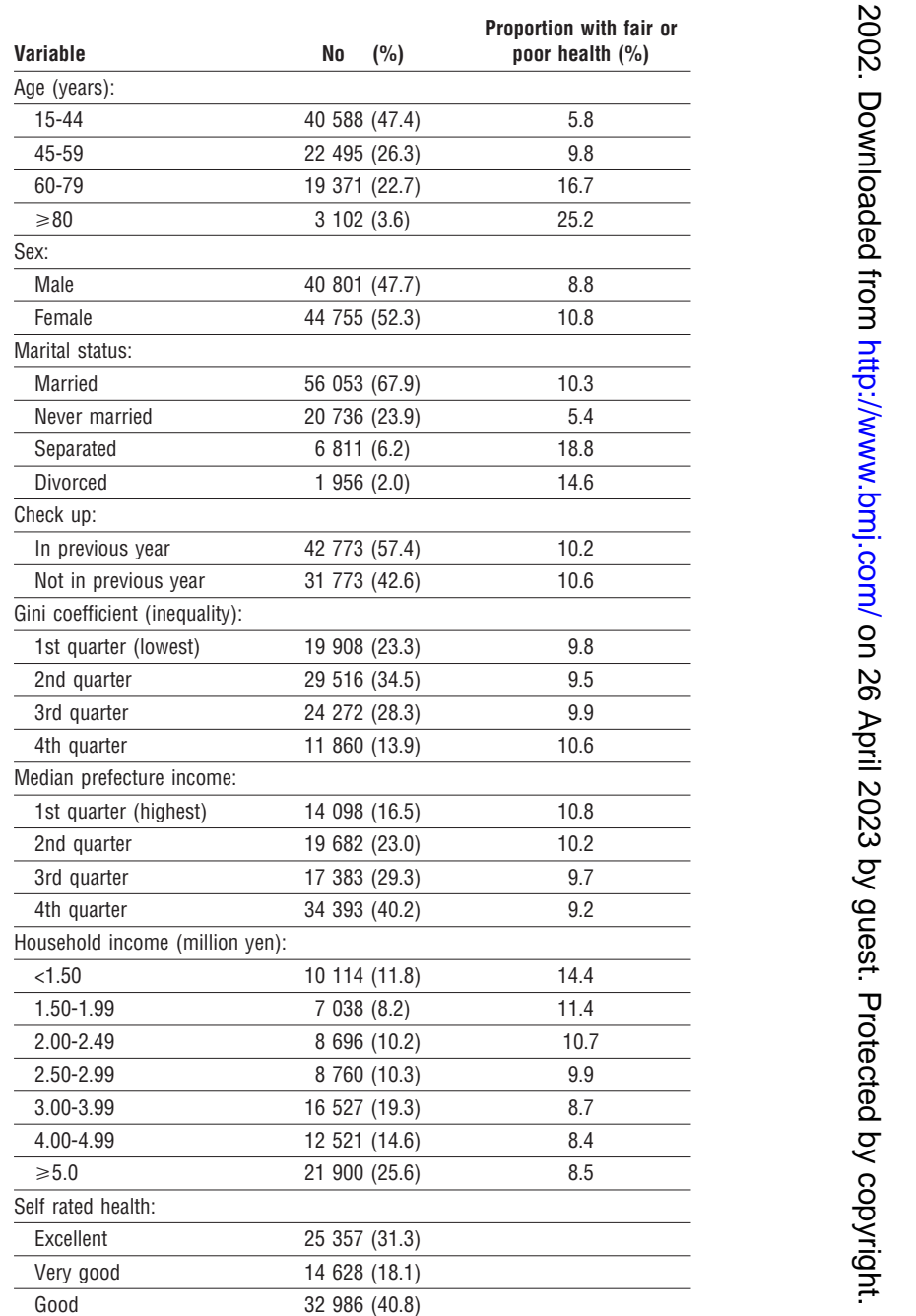

\begin{tabular}{lc}
\hline Fair & $7255(9.0)$ \\
\hline Poor & $673(0.8)$
\end{tabular}


Table 3 Univariate and adjusted odds ratios (95\% confidence intervals) for self rated health (fair or poor=1) estimated by logistic regression models

\begin{tabular}{|c|c|c|c|c|}
\hline Independent variable & Univariate & Model 1 & Model 2 & Model 3 \\
\hline Intercept & & $0.10(0.09$ to 0.11$)$ & $0.06(0.05$ to 0.06$)$ & 0.08 (0.06 to 0.11$)$ \\
\hline \multicolumn{5}{|l|}{ Prefecture level variables } \\
\hline \multicolumn{5}{|l|}{ Gini coefficient (inequality): } \\
\hline 1st quarter (lowest) & 1.00 & 1.00 & 1.00 & 1.00 \\
\hline 2nd quarter & $1.00(0.92$ to 1.10$)$ & 0.97 (0.89 to 1.07$)$ & $1.00(0.91$ to 1.11$)$ & 0.99 (0.89 to 1.11$)$ \\
\hline 3rd quarter & 1.07 (0.98 to 1.18$)$ & $1.03(0.94$ to 1.14$)$ & $1.03(0.93$ to 1.14$)$ & $1.02(0.90$ to 1.17$)$ \\
\hline 4th quarter & $1.14(1.02$ to 1.27$)$ & $0.90(0.78$ to 1.05$)$ & $0.90(0.77$ to 1.04$)$ & 1.13 (0.96 to 1.34$)$ \\
\hline \multicolumn{5}{|l|}{ Median prefecture income: } \\
\hline 1st quarter (highest) & $1.33(1.20$ to 1.47$)$ & 1.39 (1.22 to 1.58$)$ & $1.14(1.01$ to 1.30$)$ & 0.79 (0.64 to 0.99$)$ \\
\hline 2nd quarter & 1.15 (1.07 to 1.24) & $1.13(1.03$ to 1.23$)$ & $1.03(0.94$ to 1.13$)$ & 0.85 (0.71 to 1.01$)$ \\
\hline 3rd quarter & 1.15 (1.05 to 1.25$)$ & 1.11 (1.01 to 1.22$)$ & $1.03(0.94$ to 1.14$)$ & 0.93 (0.83 to 1.04$)$ \\
\hline 4th quarter & 1.00 & 1.00 & 1.00 & 1.00 \\
\hline \multicolumn{5}{|l|}{ Individual level variables } \\
\hline \multicolumn{5}{|c|}{ Household income (million yen): } \\
\hline$<1.50$ & 1.93 (1.72 to 2.15$)$ & & 1.54 (1.36 to 1.73$)$ & 1.54 (1.37 to 1.74$)$ \\
\hline $1.50-1.99$ & 1.48 (1.30 to 1.80$)$ & & 1.30 (1.14 to 1.49) & 1.30 (1.14 to 1.49$)$ \\
\hline $2.00-2.49$ & 1.38 (1.23 to 1.54) & & 1.25 (1.11 to 1.40$)$ & 1.24 (1.11 to 1.40$)$ \\
\hline $2.50-2.99$ & 1.23 (1.09 to 1.38$)$ & & 1.22 (1.08 to 1.38$)$ & 1.23 (1.09 to 1.38$)$ \\
\hline $3.00-3.99$ & 1.05 (0.95 to 1.17$)$ & & 1.08 (0.97 to 1.20$)$ & $1.08(0.97$ to 1.20$)$ \\
\hline $4.00-4.99$ & $1.01(0.91$ to 1.13$)$ & & 1.04 (0.93 to 1.17) & 1.04 (0.93 to 1.17$)$ \\
\hline$\geqslant 5.00$ & 1.00 & & 1.00 & 1.00 \\
\hline \multicolumn{5}{|l|}{ Age (years): } \\
\hline $15-44$ & 1.00 & & 1.00 & 1.00 \\
\hline $45-59$ & 1.69 (1.57 to 1.83$)$ & & 1.57 (1.44 to 1.73$)$ & 1.57 (1.43 to 1.72$)$ \\
\hline $60-79$ & 3.15 (2.92 to 3.39 ) & & 2.69 (2.46 to 2.96$)$ & 2.69 (2.45 to 2.95$)$ \\
\hline$\geqslant 80$ & $5.10(4.47-5.83)$ & & 4.30 (3.66 to 5.05$)$ & 4.29 (3.65 to 5.05$)$ \\
\hline \multicolumn{5}{|l|}{ Marital status: } \\
\hline Married & 1.00 & & 1.00 & 1.00 \\
\hline Never married & 0.53 (0.49 to 0.59$)$ & & 0.92 (0.83 to 1.02$)$ & 0.92 (0.83 to 1.02$)$ \\
\hline Separated & 1.99 (1.81 to 2.19) & & $0.99(0.88$ to 1.11$)$ & 0.99 (0.88 to 1.11$)$ \\
\hline Divorced & 1.55 (1.31 to 1.84$)$ & & 1.31 (1.11 to 1.56$)$ & 1.31 (1.10 to 1.55$)$ \\
\hline \multicolumn{5}{|l|}{ Sex: } \\
\hline Male & 1.00 & & 1.00 & 1.00 \\
\hline Female & 1.27 (1.20 to 1.34$)$ & & 1.18 (1.12 to 1.25$)$ & 1.18 (1.12 to 1.25$)$ \\
\hline \multicolumn{5}{|c|}{ Health check up in previous year: } \\
\hline Yes & 1.00 & & 1.00 & 1.00 \\
\hline No & 1.06 (0.99 to 1.13) & & 1.02 (0.96 to 1.08$)$ & 1.01 (0.95 to 1.08$)$ \\
\hline Regional block dummies & No & No & No & Yes \\
\hline Wald $\chi^{2} ; \mathrm{P}$ value & & $18594 ;<0.001$ & $20316 ;<0.001$ & $22720 ;<0.001$ \\
\hline
\end{tabular}

\section{Results}

Table 1 summarises the economic variables at individual and prefecture level used in our analysis. Median prefecture income was slightly lower than the median individual income in our sample $(3.13 \mathrm{~m}$ yen (about £21 096) v $3.48 \mathrm{~m}$ yen (about $£ 23455$ ), at the average 1995 exchange rate of 1 yen $=£ 0.00674$ ).

Distribution of prefecture level income measured by the Gini coefficient ranged from 0.31 to 0.45 with the median of 0.36. At the prefecture level, the Gini coefficient and median income showed moderate correlation (Pearson's correlation coefficient -0.51). Sample characteristics of our data are presented in table 2. Overall, $9.8 \%$ of the sample reported their health as fair $(9.0 \%)$ or poor $(0.8 \%)$.

Table 3 represents the univariate and multivariate odds ratios for the effects of income distribution at the prefecture level on individual self rated health. The Mantel-Haenszel trend test suggested that higher quarters of the Gini coefficient, lower quarters of median income, and lower categories of individual income were associated with the likelihood of self reported fair or poor health $(\mathrm{P}<0.0001$, data not shown). In model 1, in which two prefecture level vari- ables were simultaneously included, a graded association of median income remained while the effect of the Gini coefficient became weaker.

Next we adjusted for the individual characteristics of household income, age, sex, marital status, and health check up in the previous year (model 2 in table 3). Odds ratios of the Gini coefficient and median income at the prefecture level were further weakened. Instead, individual income was significantly associated with self rated health. Compared with the highest income class $(>5.00 \mathrm{~m}$ yen), adjusted odds ratios for reporting poor health ranged from $1.54 \quad(95 \%$ confidence interval 1.36 to 1.73 ) in the lowest income class $(<1.50 \mathrm{~m}$ yen) to 1.22 (1.08 to 1.38$)$ in the fourth income class $(2.50 \mathrm{~m}-2.99 \mathrm{~m}$ yen). Adjusted odds ratios of other individual level variables were also significant, including older age, being female, and being divorced. Further adjustment was made by including dummy variables for 12 geopolitical blocks (model 3 in table 3 ). While the effects of explanatory variables other than the prefecture level variables remained stable, a gradient effect of the Gini coefficient was observed: odds ratio of the highest quarter of the Gini coefficient was 1.13 (0.96 to 1.34). Median prefecture income, 
Table 4 Adjusted odds ratios (95\% confidence interval) of income inequality for reporting fair or poor health, stratified by household income, age, and sex

\begin{tabular}{|c|c|c|c|}
\hline $\begin{array}{l}\text { Stratification and } \\
\text { model }^{*}\end{array}$ & $\begin{array}{l}\text { Gini 2nd quarter } \\
\text { (lower inequality) }\end{array}$ & $\begin{array}{l}\text { Gini 3rd quarter } \\
\text { (higher inequality) }\end{array}$ & $\begin{array}{l}\text { Gini 4th quarter } \\
\text { (highest inequality) }\end{array}$ \\
\hline \multicolumn{4}{|c|}{ Income (million yen) } \\
\hline \multicolumn{4}{|l|}{$<2.00$ : } \\
\hline Model 2 & $1.10(0.87$ to 1.38$)$ & $1.07(0.85$ to 1.34$)$ & 1.04 (0.78 to 1.37$)$ \\
\hline Model 3 & $1.05(0.81$ to 1.36$)$ & $1.07(0.79$ to 1.44$)$ & 1.27 (0.90 to 1.78$)$ \\
\hline \multicolumn{4}{|l|}{ 2.00-2.99: } \\
\hline Model 2 & 0.87 (0.71 to 1.07$)$ & $0.99(0.82$ to 1.19$)$ & 0.86 (0.65 to 1.13$)$ \\
\hline Model 3 & $0.83(0.65$ to 1.05$)$ & $0.82(0.64$ to 1.05$)$ & 0.88 (0.64 to 1.21$)$ \\
\hline \multicolumn{4}{|l|}{ 3.00-4.99: } \\
\hline Model 2 & $1.06(0.90$ to 1.25$)$ & $1.11(0.94$ to 1.30$)$ & 0.87 (0.66 to 1.15$)$ \\
\hline Model 3 & 1.04 (0.86 to 1.26$)$ & 1.10 (0.89 to 1.35$)$ & 1.20 (0.89 to 1.62$)$ \\
\hline \multicolumn{4}{|l|}{$>5.00$ : } \\
\hline Model 2 & $0.98(0.82$ to 1.17$)$ & $0.95(0.77$ to 1.16$)$ & 0.86 (0.63 to 1.17$)$ \\
\hline Model 3 & 1.02 (0.83 to 1.25$)$ & 1.06 (0.83 to 1.35$)$ & 1.07 (0.74 to 1.56$)$ \\
\hline \multicolumn{4}{|l|}{ Age (years) } \\
\hline \multicolumn{4}{|l|}{$>60:$} \\
\hline Model 2 & $0.97(0.84$ to 1.12$)$ & $1.04(0.90$ to 1.19$)$ & 0.88 (0.71 to 1.09$)$ \\
\hline Model 3 & $0.90(0.67$ to 1.23$)$ & $0.92(0.71$ to 1.19$)$ & 0.98 (0.84 to 1.16$)$ \\
\hline \multicolumn{4}{|l|}{$\leqslant 60$ : } \\
\hline Model 2 & $1.02(0.91$ to 1.15$)$ & $1.02(0.90$ to 1.15$)$ & 0.94 (0.78 to 1.14$)$ \\
\hline Model 3 & 1.01 (0.88 to 1.16$)$ & 0.99 (0.85 to 1.16$)$ & 1.20 (0.98 to 1.49$)$ \\
\hline \multicolumn{4}{|l|}{ Sex } \\
\hline \multicolumn{4}{|l|}{ Male: } \\
\hline Model 2 & $1.04(0.91$ to 1.18$)$ & $1.05(0.91$ to 1.20$)$ & 0.92 (0.75 to 1.13$)$ \\
\hline Model 3 & $1.02(0.87$ to 1.18$)$ & $1.07(0.90$ to 1.28$)$ & 1.22 (0.98 to 1.53$)$ \\
\hline \multicolumn{4}{|l|}{ Female: } \\
\hline Model 2 & $0.98(0.86$ to 1.11$)$ & $1.02(0.83$ to 1.15$)$ & 0.91 (0.76 to 1.09 ) \\
\hline Model 3 & 0.98 (0.85 to 1.13$)$ & 0.99 (0.84 to 1.16$)$ & 1.09 (0.88 to 1.36$)$ \\
\hline
\end{tabular}

* Model 2=adjusted for prefecture median income, Gini coefficient, household income, and individual characteristics; model $3=$ model 2 plus dummy variables for geopolitical blocks.

however, showed a reversed gradient against perceived health: individuals in the lowest income quarter were $21 \%$ less likely to report poor health (odds ratio 0.79 , $95 \%$ confidence interval 0.64 to 0.99 ).

We also examined the effects of income distribution stratified by income, age, and sex to test whether income inequality affects all individuals equally or only subpopulations in a society (table 4). In each stratum, however, none of the models suggested differential effects of income inequality on self rated health across strata.

\section{Discussion}

In this cross sectional analysis of a nationally representative sample in Japan we have shown that individual income, probably relative to median income at the prefecture level, has a stronger association with an individual's self rated health compared with income inequality at the prefecture level.

The few studies that have examined the effects of income and its distribution on individual self rated health were exclusively carried out in the United States. ${ }^{91-16}$ Although they drew mixed conclusions, their findings were somewhat similar. The negative effect of income inequality on perceived health was attenuated when adjustment was made for individual level income and other explanatory variables. Furthermore, the effect of inequality in individual income was stronger than that of inequality in regional income. ${ }^{10-13}$ Our study also confirms this finding.

A study by Mellor and Milyo was unique in that they included regional fixed effects to control for nonspecific regional characteristics. ${ }^{13}$ They showed that, after inclusion of regional effects, state mean income was inversely related to self rated health. We also found a reversed gradient of the effects of median income on subjective health. A negative gradient of prefecture level income along with a positive gradient of individual income indicates that level of individual income, relative to level of regional income, may be associated with individual health. ${ }^{10}$ On the other hand, the effect of income inequality on health was smaller in our study than in previous studies in the United States. ${ }^{12}{ }^{13}$ Several explanations can be proposed for the disparity.

\section{Reasons for disparity with other studies}

Firstly, the magnitude of income inequality in Japan may still be small and the significant association between income inequality and health may be observed only at the levels of inequality present in the United States. ${ }^{26}$ Some researchers report, however, that income inequality in Japan has rapidly increased since the late $1980 \mathrm{~s} .^{19}$ In fact, the mean Gini coefficient in Japan in 1995 was 0.36 and already comparable with those in European countries, although it is still below the level of income inequality in the United States. ${ }^{22}{ }^{27}$ Alternatively, there may be a time lag between the prevalence of income inequality and its effects on health. For example, Blakely et al have shown that income inequality measured up to 15 years previously was more strongly associated with self rated health than contemporary measurement. ${ }^{28}$ Therefore, time series analysis of Japanese data would also be needed in a future study. ${ }^{5}{ }^{15}$

Secondly, the units of aggregation in our study (that is, prefectures) may be too homogeneous for income distribution to exert an effect independent of individual income. However, the aggregation in a geopolitical level, larger than the prefectures, yielded similar results (data not shown). We decided to use prefecture as the primary unit of aggregation because a prefecture is similar to a state in the United States in terms of its population size and variations in income inequality.

Finally, the relation between income inequality and health may not be universal but instead may depend on social and political characteristics specific to place and cultural norms. Several researchers attribute the significant effect of income inequality in the United States to the degree of economic segregation that may lead to lack of investment in public goods. ${ }^{29}{ }^{30} \mathrm{~A}$ recent ecological study in Taiwan also provides limited evidence of changes in association between income inequality and health status, depending on the stage of economic development and social transformation. ${ }^{6}$

Our results do not mean that we should not be concerned with reducing income inequality. Inequality in income at state level in the previous studies may reflect various social conditions, including the effects of local policies that cannot easily be observed but vary across states. ${ }^{106}{ }^{30}$ Further inquiry into the theoretical basis and conceptual framework of the relation between income distribution and health will enhance our understanding of the reasons why income inequality affects health in some countries and not in others.

Contributors: KS and HH conceived the study, analysed the data, and interpreted the results. EY helped to interpret the 


\section{What is already known on this topic}

Contrary to the common perception of an egalitarian society, income inequality in Japan has increased rapidly since the late 1980 s, though life expectancy continues to increase

Individual level studies, exclusively carried out in the United States to assess the independent effects of income inequality on health, have had mixed results

\section{What this study adds}

Individual income levels, probably relative to regional median income, may have more influence on an individual's perceived health than regional income inequality in Japan

results. KS drafted the paper, which was edited by $\mathrm{HH}$ and EY $\mathrm{KS}$ and $\mathrm{HH}$ are joint guarantors.

Funding: This study was in part supported by a grant from the Japan Ministry of Health, Labour and Welfare (No 100-50101)

Competing interests: None declared.

1 Rodgers GB. Income and inequality as determinants of mortality: an international cross-section analysis. Popul Stud Camb 1979;33:343-51.

2 Wilkinson RG. Income distribution and life expectancy. BMJ 1992;304:165-8

3 Ben-Shlomo Y, White IR, Marmot M. Does the variation in the socioeconomic characteristics of an area affect mortality? BMJ 1996;312:1013-4

4 Kaplan GA, Pamuk ER, Lynch JW, Cohen RD, Balfour JL. Inequality in income and mortality in the United States: analysis of mortality and potential pathways. BMJ 1996;312:999-1003.

5 Kennedy BP, Kawachi I, Prothrow-Stith D. Income distribution and mortality: cross-sectional ecological study of the Robin Hood index in the United States. BMJ 1996;312:1004-7.

6 Chiang T. Economic transition and changing relation between income inequality and mortality in Taiwan: regression analysis. BMJ $1999 \cdot 319: 1162-5$

7 Kawachi I, Kennedy BP. Income inequality and health: pathways and mechanisms. Health Serv Res 1999;34:215-27.

8 Gravelle $\mathrm{H}$. How much of the relation between population mortality and unequal distribution of income is a statistical artefact? $B M J$ 1998;316:382-5.

9 Fiscella K, Franks P. Poverty or income inequality as predictor of mortality: longitudinal cohort study. BMJ 1997;314:1724-7.

10 Wagstaff A, van Doorslaer E. Income inequality and health: what does the literature tell us? Annu Rev Public Health 2000;21:543-67.
11 Mellor JM, Milyo J. Income inequality and health status in the United States: evidence from the current population survey. Princeton, NJ: Robert Wood Johnson Foundation, 2000.

12 Soobader MJ, LeClere FB. Aggregation and the measurement of income inequality: effects on morbidity. Soc Sci Med 1999;48:733-44

13 Kennedy BP, Kawachi I, Glass R, Prothrow-Stith D. Income distribution, socioeconomic status, and self rated health in the United States: multilevel analysis. BMJ 1998;317:917-21.

14 LeClere FB, Soobader MJ. The effect of income inequality on the health of selected US demographic groups. Am J Public Health 2000;90:1892-7.

15 Kahn RS, Wise PH, Kennedy BP, Kawachi I. State income inequality, household income, and maternal mental and physical health: cross sectional national survey. BMJ 2000;321:1311-5.

16 Daly MC, Greg JD, Kaplan GA, Lynch JW. Macro-to-micro links in the relation between income inequality and mortality. Milbank $Q$ 1998;76: 315-39.

17 Marmot MG, Smith GD. Why are the Japanese living longer? BMJ 1989;299:1547-51

18 Wilkinson RG. The epidemiological transition: from material scarcity to social disadvantage? Daedalus 1994:123:61-77.

19 Tachinabaki T. Economic disparity in Japan. Tokyo: Iwanami, 1998. (In Japanese.)

20 Ministry of Health and Welfare. Kokumin Seikatsu Kiso Chosa. Tokyo: Statistics and Information Department Minister's Secretariat, 1995 (Comprehensive Survey of the Living Conditions of People on Health and Welfare.)

21 Idler EL, Benyamini Y. Self-rated health and mortality: a review of twenty-seven community studies. J Health Soc Behav 1997;38:21-37.

22 Atkinson AB, Rainwater L, Smeeding M. Income distribution in OECD countries. Evidence from Luxembourg income study. Paris: Organization for Economic Cooperation and Development, 1995.

23 Kawachi I, Kennedy BP. The relationship of income inequality to mortality: does the choice of indicator matter? Soc Sci Med 1997;45:1121-7

24 Brick JM, Kalton G. Handling missing data in survey research. Stat Meth ods Med Res 1996;5:215-38.

25 Brogan DJ. Software for sample survey data, misuse of standard packages In: Armitage P, Colton T, editors. Encyclopedia of biostatistics. Vol 5. New York: John Wiley, 1998:4167-74

26 Blakely T, Woodward A, Razum O, Ross NA, Wolfson M, Berthelot J-M, et al. Income inequality and mortality in Canada and the United States. Third explanation is plausible. $B M J$ 2000;321:1532.

27 Income Statistics Branch/HHES Division. Measures of household incom inequality: 1967 to 1999. Supplemental income inequality tables. Washington, DC: US Census Bureau, 2001. www.census.gov/hhes/income/histinc/ ie6.html (accessed 23 Oct 2001)

28 Blakely TA, Kennedy BP, Glass R, Kawachi I. What is the lag time between income inequality and health status? J Epidemiol Community Healt 2000;54:318-9.

29 Ross NA, Wolfson MC, Dunn JR, Berthelot JM, Kaplan GA, Lynch JW. Relation between income inequality and mortality in Canada and in the United States: cross sectional assessment using census data and vital statistics. BMJ 2000;320:898-902.

30 Lynch JW, Smith GD, Kaplan GA, House JS. Income inequality and mortality: importance to health of individual income, psychosocial environment, or material conditions. BMJ 2000;320:1200-4.

(Accepted 29 August 2001) 